\title{
Therapeutic drug monitoring and tyrosine kinase inhibitors (Review)
}

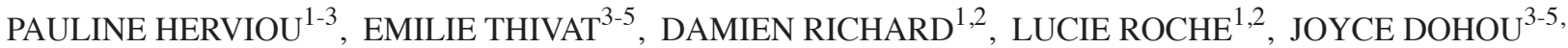 \\ MÉLANIE POUGET $^{3,5,6}$, ALAIN ESCHALIER ${ }^{1,2,7}$, XAVIER DURANDO $^{3,5,8}$ and NICOLAS AUTHIER ${ }^{1,2,7}$ \\ ${ }^{1}$ Department of Pharmacology, CHU Clermont-Ferrand, Clermont-Ferrand F-63003; ${ }^{2}$ INSERM U 1107, Neuro-Dol, \\ Clermont-Ferrand F-63000; ${ }^{3}$ Centre Jean Perrin; ${ }^{4}$ ERTICa EA 4677, Research Team on Individualized Treatment of \\ Cancers in Auvergne, Auvergne University and Centre Jean Perrin, Clermont-Ferrand F-63011; \\ ${ }^{5}$ INSERM UMR 990, Auvergne University; ${ }^{6}$ Clinical Investigation Center, INSERM U 501; ${ }^{7}$ Department of \\ Fundamental and Clinical Pharmacology of Pain, Auvergne University, Clermont-Ferrand F-63000; \\ ${ }^{8}$ CREaT EA 3846, Cancer Resistance Exploring and Targeting, Auvergne University \\ and Centre Jean Perrin, Clermont-Ferrand F-63011, France
}

Received July 13, 2015; Accepted April 25, 2016

DOI: $10.3892 / \mathrm{ol} .2016 .4780$

\begin{abstract}
The therapeutic activity of drugs can be optimized by establishing an individualized dosage, based on the measurement of the drug concentration in the serum, particularly if the drugs are characterized by an inter-individual variation in pharmacokinetics that results in an under- or overexposure to treatment. In recent years, several tyrosine kinase inhibitors (TKIs) have been developed to block intracellular signaling pathways in tumor cells. These oral drugs are candidates for therapeutic drug monitoring (TDM) due to their high inter-individual variability for therapeutic and toxic effects. Following a literature search on PubMed, studies on TKIs and their pharmacokinetic characteristics, plasma quantification and inter-individual variability was studied. TDM is commonly used in various medical fields, including cardiology and psychiatry, but is not often applied in oncology. Plasma concentration monitoring has been thoroughly studied for imatinib, in order to evaluate the usefulness of TDM. The measurement of plasma concentration can be performed by various analytical techniques, with liquid chromatography-mass spectrometry being the reference method. This method is currently used to monitor the efficacy and tolerability of imatinib treatments. Although TDM is already being used for imatinib, additional studies are required in order to improve this practice with the inclusion of other TKIs.
\end{abstract}

Correspondence to: Ms. Pauline Herviou, Department of Pharmacology, CHU Clermont-Ferrand, 58 Rue Montalembert, BP 69, Clermont-Ferrand F-63003, France

E-mail: herviou.pauline@gmail.com

Key words: therapeutic drug monitoring, tyrosine kinase inhibitor, pharmacokinetics, plasma concentration, target value

\section{Contents}

1. Introduction

2. Practical issues in TDM: Application for routine analysis

3. Pharmacokinetics of TKIs

4. Variability in pharmacokinetic parameters

5. Correlation between TKI plasma concentration and therapeutic effect

6. Conclusion

\section{Introduction}

Therapeutic drug monitoring (TDM) is the measure of the drug concentration in the blood, in order to adapt the dosage $(1,2)$. TDM is already used for drug classes such as antibiotics, immunosuppressants and, more recently, antiretroviral drugs (1). TDM allows for the determination of the actual drug concentration in the body. To study the pharmacokinetics of a molecule, three parameters are typically measured: The residual concentration, serum peak and area under the curve (AUC). The residual concentration (C0) refers to the drug concentration measured just before the administration of the next dose. This measurement is characterized by its easy sample collection and low cost; however, it can sometimes lead to dose modifications being performed too frequently (1). The serum peak drug concentration is the maximum concentration of the drug reached in the body, in a steady state. This is achieved by the accumulation of the molecule in the body until an equilibrium is reached, in which the concentration peak no longer increases $(1,3)$. The third parameter is the measured AUC, which refers to the index of the total drug exposure. The measurement of AUC helps to determine whether the kinetics of the patient are classic, thus highlighting inter-individual variability in the metabolism or excretion of the drug.

The pharmacokinetic parameters of a drug are influenced by several factors: Genetic (slow and fast metabolizers), 
physiological (age), pathological (renal or liver failure) and environmental (food) (4). These factors are important role in the pharmacokinetics of a molecule, since at the same dosage, the plasma concentration of a drug can differ from patient to patient, leading to variations in the therapeutic responses obtained, as well as the occurrence of adverse effects (4). Anticancer drugs are good candidates for TDM, since they exhibit different parameters that are required for a molecule to be eligible for TDM: Narrow therapeutic window between efficacy and toxicity; significant inter-individual variability (bioavailability and metabolism); therapeutic concentration effect; associations between plasma concentration and toxic/therapeutic effect; drug interactions or intercurrent diseases that may interfere with the kinetics, and finally, the possibility of interpreting the plasma concentrations using the appropriate quantification method (2). However, TDM is rarely applied in clinical oncology, mainly due to a lack of pharmacokinetic data and optimal values. The limited use of TDM may also be due to certain analytical difficulties, either technical or faced during the interpretation of the results, such as the presence of an active metabolite, and determination of the free vs. tumor concentration of the drug (2).

Tyrosine kinase inhibitors (TKIs) are a class of targeted therapy used in the treatment of malignant diseases $(5,6)$. The most well known TKI is imatinib, which is used in patients with chronic myeloid leukemia (CML) $(5,6)$. TKIs compete with adenosine triphosphate (ATP) at its binding site $(5,6)$. This inhibits tyrosine kinase, which is involved in several pathways, including tumor cell growth and proliferation, as well as suppression of apoptosis and promotion of angiogenesis (5). TKIs have been demonstrated to be efficient in monotherapy and in combination with chemotherapy. There are currently 17 Food and Drug Administration (FDA)-approved TKIs $(7,8)$ for various indications (9), as indicated in Table I.

Imatinib mesylate (Gleevec ${ }^{\circledR}$ or Glivec ${ }^{\circledR}$; Novartis), the oldest TKI, is indicated for the treatment of CML and gastrointestinal stromal tumors (GIST) (6). Imatinib mesylate is a competitive inhibitor of the fusion protein breakpoint cluster region-Abelson oncoprotein (BCR-ABL), which is responsible for the increased proliferation of leukemic cells and their resistance to apoptosis (10).

In the last decade, second generation TKIs have been introduced into routine practice. Among them, dasatinib (Sprycel ${ }^{\circledR}$; Bristol-Myers Squibb) and nilotinib (Tasigna ${ }^{\circledR}$; Novartis), are used for the treatment of CML and acute lymphoblastic leukemia (ALL), if imatinib fails (10).

Nilotinib shares the same mechanism with imatinib, but has a higher inhibitory activity (11). In a phase II clinical trial, out of the 321 patients with CML treated with $400 \mathrm{mg}$ nilotinib twice a day, $226(70 \%)$ were imatinib-resistant and $95(30 \%)$ imatininb-intolerant. The main adverse events observed at the 24-month follow-up were rash (31\%), pruritus $(26 \%)$ and nausea (25\%). Adverse events led to the discontinuation of the treatment for 53 patients. At 24 months, $59 \%$ of the patients had achieved a major cytogenetic response and $45 \%$ a complete response. At 48 months, the rate of progression-free survival was $57 \%$ (11).

Dasatinib is a multi-kinase inhibitor prescribed to patients with CML and ALL, who are intolerant or resistant to imatinib (6). A study was conducted on 387 patients with
CML in chronic phase who were resistant or intolerant to imatinib to estimate the rate of major cytogenetic response at 6 and 8 months.. Patients were treated with dasatinib at a dose of $70 \mathrm{mg}$ twice daily, in chronic phase (12). A complete hematologic response was obtained in $90 \%$ of patients $(80 \%$ of imatinib-resistant patients and $97 \%$ of imatinib-intolerant patients). Dasatinib also induced a major cytogenetic response in $52 \%$ of patients (39\% of imatinib-resistant patients and $80 \%$ of imatinib-intolerant patients), which was maintained in 96 and $100 \%$ of the above patients, respectively, during 8 months (12). In that study, dasatinib was well tolerated, with only $9 \%$ of patients discontinuing their treatment after 8 months, due to adverse effects. Dasatinib has been approved by the FDA for the treatment of CML and Philadelphia chromosome (Ph)-positive ALL (13).

Bosutinib (Bosulif ${ }^{\circledR}$; Pfizer) is another TKI that has been recently approved for the treatment of patients at different stages of CML (14). Like dasatinib, bosutinib is an inhibitor of BCR-ABL and sarcoma oncoprotein (14). In a study involving 288 patients with chronic phase CML (200 of which were resistant or intolerant to imatinib) treated with $500 \mathrm{mg}$ bosutinib daily, a major cytological response was reported at 24 months in $31 \%$ of patients (33\% of imatinib-resistant patients and $27 \%$ of imatinib-intolerant patients) (15). The most frequently observed non-hematologic adverse events were diarrhea $(84 \%)$, nausea $(44 \%)$, rash $(44 \%)$ and vomiting (35\%). Grade 3-4 neutropenia was observed in $18 \%$ of patients, thrombocytopenia in 24\% of and anemia in $13 \%$ (15).

Sunitinib (Sutent ${ }^{\circledR}$; Sugen) is a multitarget TKI approved for the treatment of advanced renal cell carcinoma (RCC) and GIST, following disease progression or in case of intolerance to imatinib (6). A total of 63 patients with metastatic RCC previously treated with cytokines were enrolled in a phase II study (16). Out of the 63 patients, 25 achieved partial remission (40\%). Median time to disease progression was 8.7 months. Observed toxicities included asthenia (38\%), decline of cardiac ejection fraction $(13 \%)$ and elevated serum lipase without clinical pancreatitis (24\%).

Other TKIs are also used for various pathologies; for example, gefitinib (Iressa ${ }^{\circledR}$; AstraZeneca), erlotinib (Tarceva ${ }^{\circledR}$; Genentech), afatinib (Giotrif ${ }^{\circledR}$; Boehringer Ingelheim) or crizotinib (Xalkori ${ }^{\circledR}$; Pfizer) can be used for the treatment of non-small cell lung cancer (NSCLC), lapatinib (Tyverb ${ }^{\circledR}$; GlaxoSmithKline) for the treatment of human epidermal growth factor-positive breast cancer, and regorafenib (Stivarga ${ }^{\circledR}$; Bayer) for the treatment of metastatic colorectal cancer.

\section{Practical issues in TDM: Application for routine analy- sis}

The current reference analytical method for the measurement of anticancer agent concentration in the plasma is liquid chromatography with tandem mass spectrometry (LC-MS/MS) (7). High-performance liquid chromatography (HPLC) is a technique used for the analytical separation of the constituents present in a complex matrix (17). To identify the different molecules, the chromatography is coupled to a detector. There are several types of detectors; the most frequently used for TDM are MS, MS/MS and ultraviolet (UV) diode array detector (18-66) (Table II). HPLC coupled with UV 


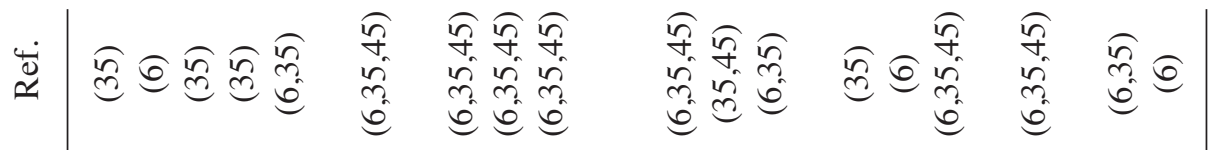

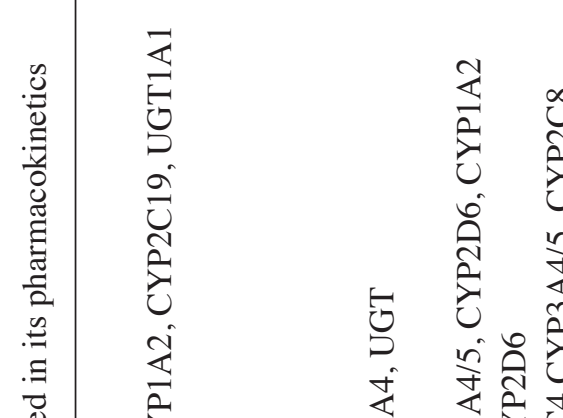

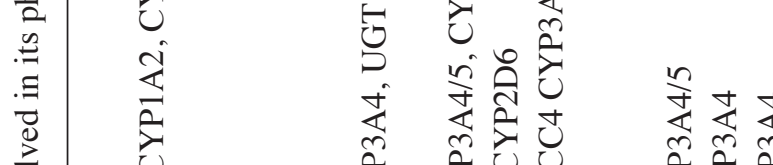

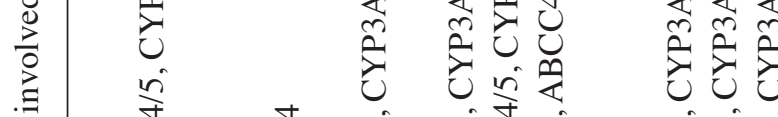

离

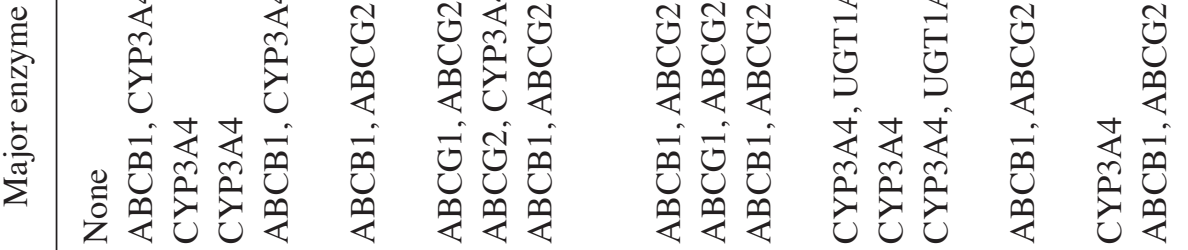

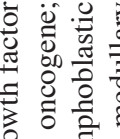

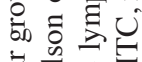

奈

论

罂这

递

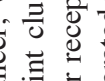

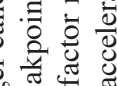

焉尊

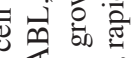

完

年

ut

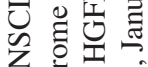

i

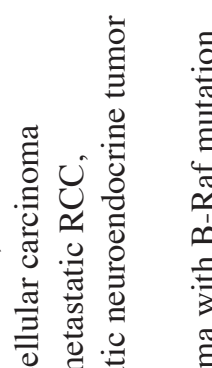

을

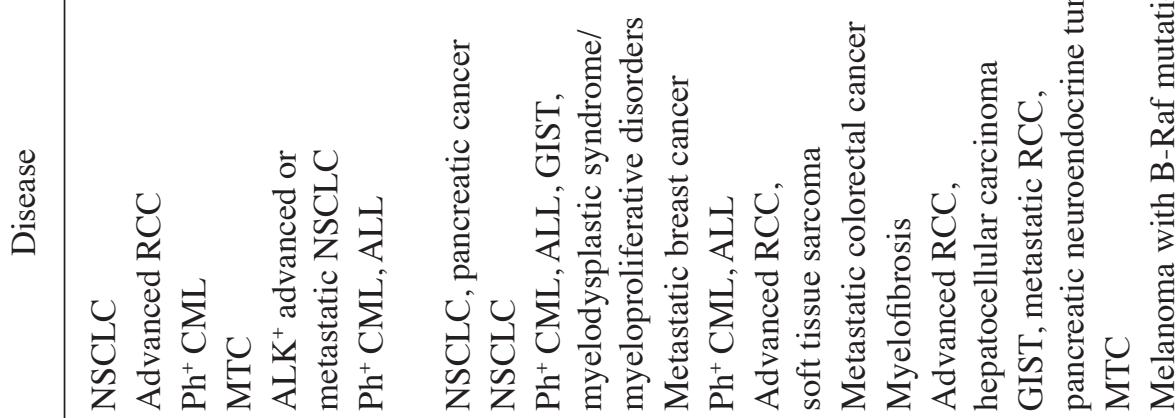

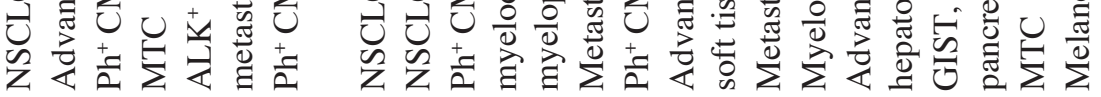

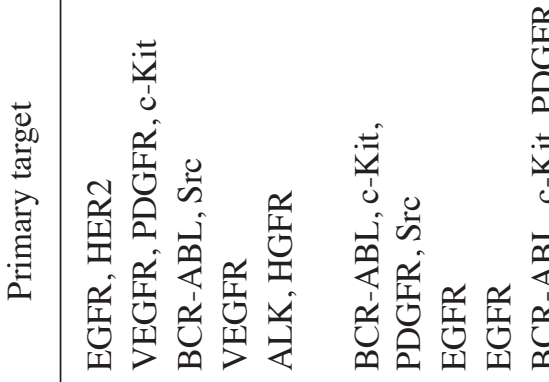

釒

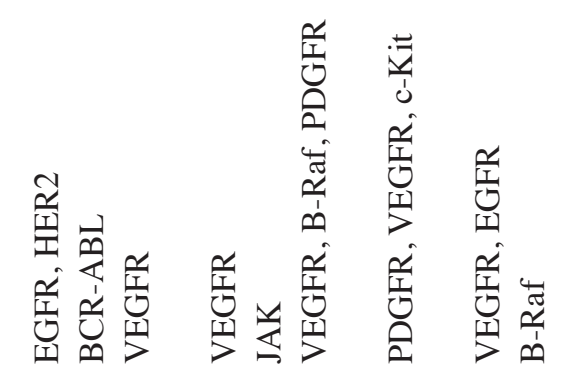

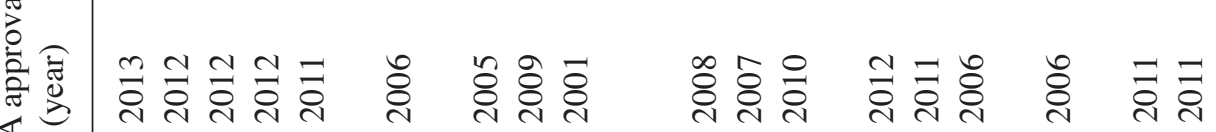
¿ 全

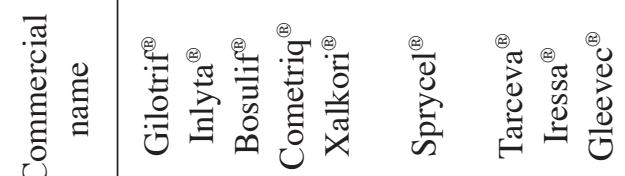

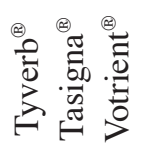

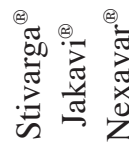

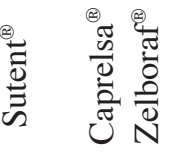

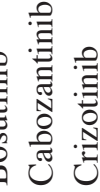

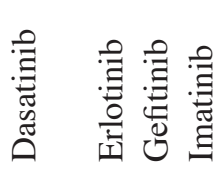

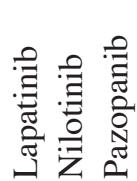

逮完器

它

애을

3) 을

韦

作

部安考

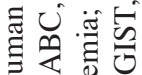

ن 语部

폴.뭉

站

흥흘

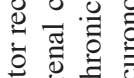

总

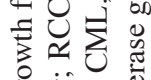

to

过

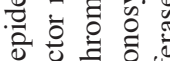

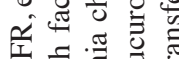

品

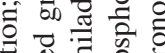

엘

. W

言

此

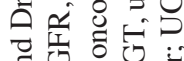

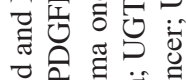

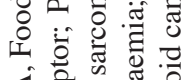

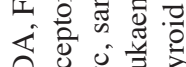



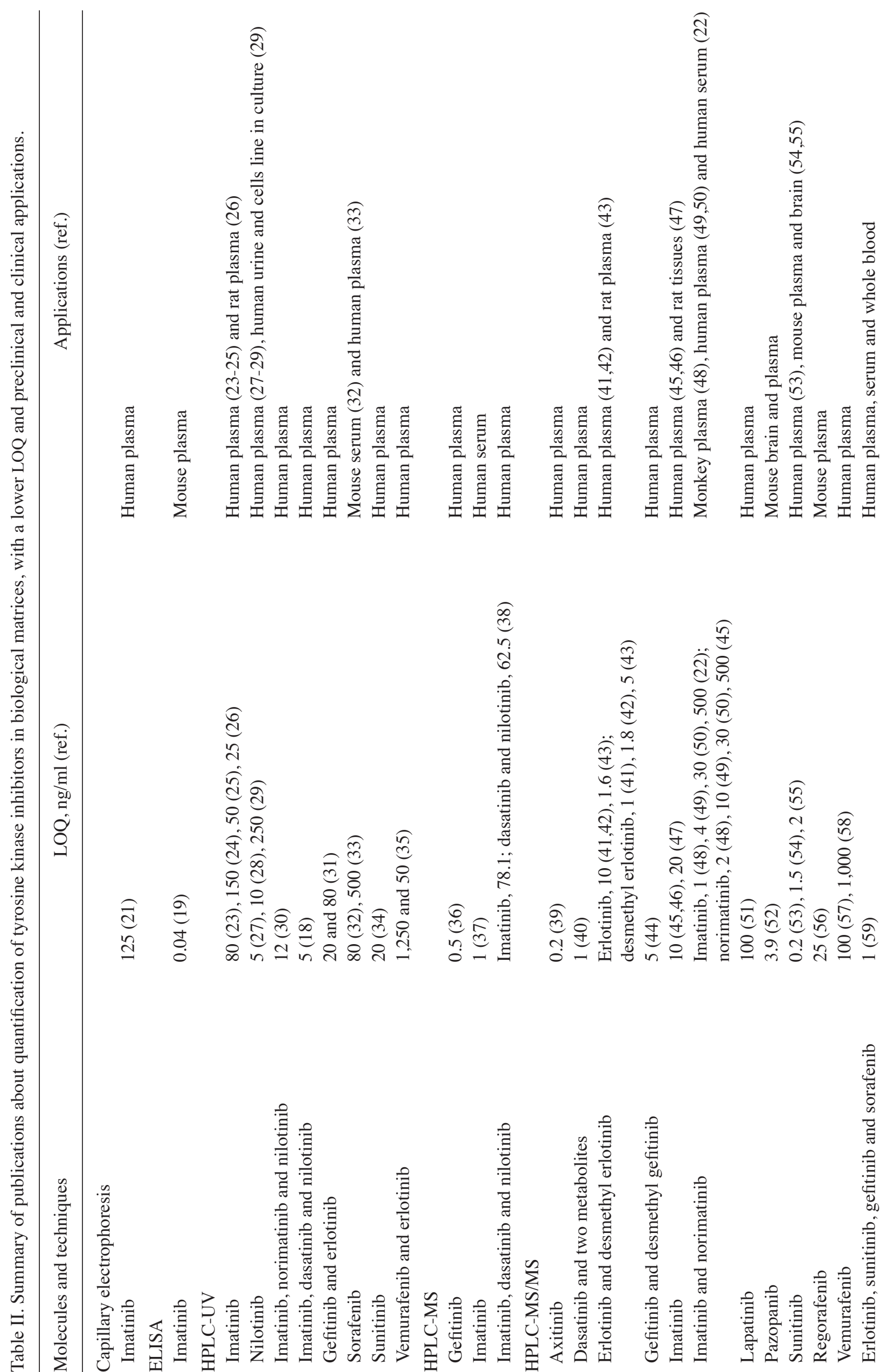


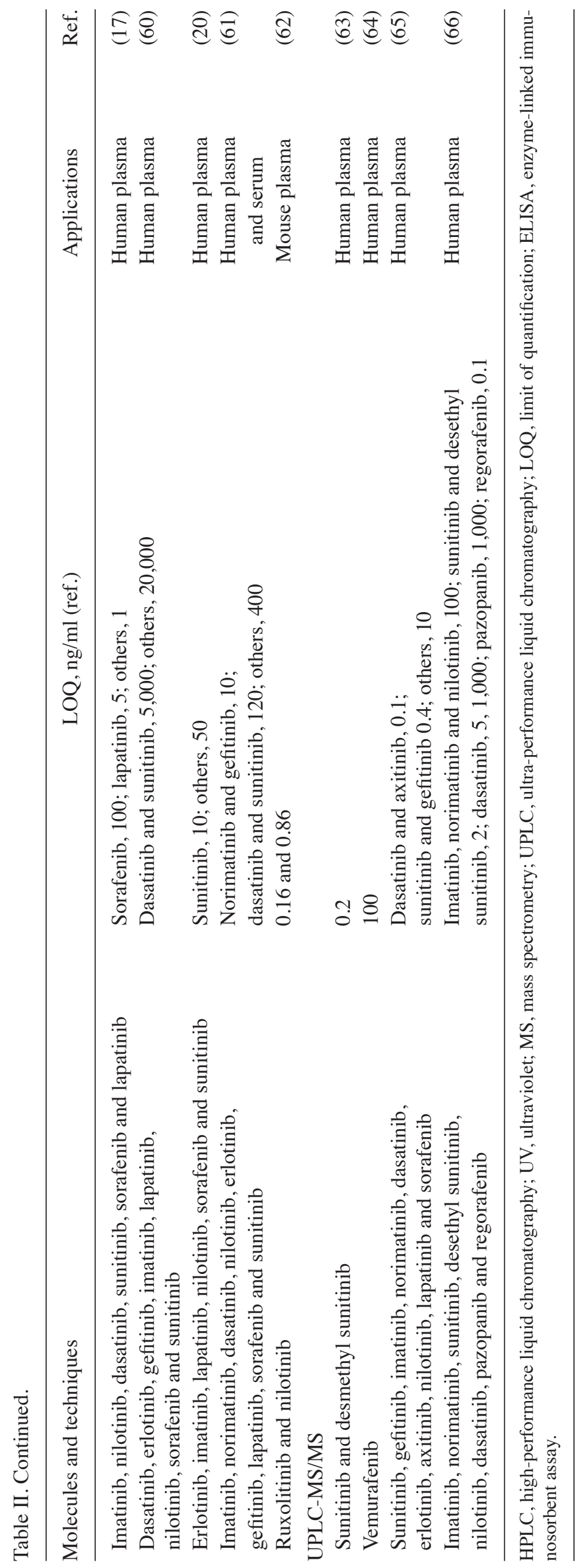


(HPLC-UV) or with other fluorescence detectors can be used as an alternative in laboratories not equipped with LC-MS/MS machinery (18). In clinical studies of pharmacokinetics and TDM of TKIs, the assays were carried out with LC-MS/MS, which is specific, sensitive and reproducible (19).

HPLC coupled to MS (HPLC-MS) has become the reference method for the quantification of large volumes of drugs in biological fluids (20). The coupling of these two techniques combines the advantages of chromatography (high separation selectivity and efficiency) with the advantages of MS (obtaining information on the structure, increase in mass and selectivity) (67). Consequently, the combination of TKIs has been used as a strategy to prevent the development of resistance against these molecules. In addition, it induces a rapid and effective response (68). It is therefore important to apply an analytical method for the quantification of several molecules simultaneously, while maintaining a reduced sample volume, such as HPLC-MS, which is a robust technique also used for the separation and quantification of a molecule and its metabolite(s) (imatinib and norimatinib, sunitinib and $\mathrm{N}$-desmethylsunitinib), which is not necessarily possible with other assay methods (20). For certain TKIs such as dasatinib, the therapeutic target is relatively low (2.5 ng/ml for dasatinib vs. $1,000 \mathrm{ng} / \mathrm{ml}$ for imatinib) (7). In these cases, LC-MS/MS is well suited, since it enables the determination of low plasmatic concentrations of drugs (7). The main disadvantage of LC-MS/MS is its cost, which is considerably higher than that of other methods (7). In addition to the high cost of this technique, it is also necessary to have specific and technical knowledge about LC-MS/MS in order to develop and validate quantitative methods in a laboratory.

\section{Pharmacokinetics of TKIs}

Adherence. Oral therapy can potentially be administered for a long period of time. It has been shown that adherence is often better in patients treated for acute diseases, as opposed to chronic ones, and often adherence stops after the first 6 months of treatment interruption (69). Patients may not understand the point of continuing their treatment following the disappearance of the symptoms, as it may be the case in CML (18); however, treatment termination can lead to a reduced efficacy. In 87 patients with CML in chronic phase treated with imatinib ( $400 \mathrm{mg} /$ day), the high rate of adherence was significantly associated with a major molecular response $(\mathrm{P}<0.001)(70)$.

Absorption and distribution. The absorption of TKIs occurs a few hours after dose administration, with a bioavailability of $60-80 \%$, depending on the molecules (6). Concomitant food intake tends to increase these values. Following absorption, $>90 \%$ of TKIs are bound to plasma proteins (albumin and $\alpha-1$-acid glycoprotein); however, only free drugs are in an active pharmacological form $(6,71)$. Numerous transport systems including ATP-binding cassette transporters, contribute to the distribution of TKIs (72). Limited data have been published on the impact of polymorphism of ATP-binding cassette transporters on TKI distribution.
Metabolism. TKIs are metabolized mainly by cytochrome P450 3A4 (CYP3A4) (Table I), sometimes to an active metabolite, such in the case of imatinib, dasatinib and sunitinib (9). The activity of CYP3A4 is regulated by various factors, including drug interactions, genetic variability or age, and comorbidities (72). Furthermore, the enzymatic activity of CYP3A4 can be induced or inhibited by co-medication (72). In the case of prodrugs, which require metabolic activation, the inhibition of biotransformation enzymes leads to an increased drug concentration and higher toxicity frequency, or may result in reduced drug effect (73). In addition, several CYP isoforms are polymorphic, which can modify the enzyme activity. Increased or decreased exposure, due to an alteration in CYP activity, may lead to clinically relevant toxic effects or altered efficiency of the treatment with TKIs (21). Following the administration of a given dose of the molecule, a large inter-individual variability of blood levels can be observed among patients (21).

\section{Variability in pharmacokinetic parameters}

The marked variability among individuals results in variable circulating blood levels of TKIs, influenced by physiological and pathophysiological changes in each patient (7). At a given dose, plasma concentrations may vary among different patients and lead to an over- or under-exposure, resulting in treatment failure or occurrence of adverse effects (20), as observed for example with imatinib (7). Monitoring the concentration of TKIs in plasma can help to evaluate treatment efficiency, patient compliance and potential interactions with other molecules that influence their pharmacokinetic parameters. Certain studies have already reported a wide variability in the plasma levels of imatinib among different patients, which suggests that adequate plasma levels are important for an optimal clinical response (74-76). The measurement and monitoring of residual plasma levels of imatinib are already being used to evaluate the course of patients treated for CML (21); however, this monitoring is yet to be applied to other TKIs.

\section{Correlation between TKIs' plasma concentration and therapeutic effect}

Imatinib. Previous studies have reported a correlation between trough plasma concentrations of imatinib and the clinical response of patients with CML (74-78). Larson et al (74) studied this correlation in 351 patients treated with $400 \mathrm{mg}$ imatinib. Blood samples were obtained from the patients after 29 days of treatment, the period corresponding to the equilibrium state. The plasma concentrations of imatinib and norimatinib were determined using HPLC-MS/MS, and were $979 \pm 530 \mathrm{ng} / \mathrm{ml}$ and $106 \pm 106 \mathrm{ng} / \mathrm{ml}$, respectively. The residual concentration of imatinib was $<647 \mathrm{ng} / \mathrm{ml}$ in 87 patients, $647-1,170 \mathrm{ng} / \mathrm{ml}$ in 178 patients, $>1,170 \mathrm{ng} / \mathrm{ml}$ in 86 patients and $>2,000 \mathrm{ng} / \mathrm{ml}$ in 19 patients. The residual concentration of imatinib in patients who achieved a complete cytogenetic response was significantly higher than that of patients who did not achieved such response $(\mathrm{P}=0.004)$, whose mean value was $1,099 \pm 544 \mathrm{ng} / \mathrm{ml}$. Maintaining the imatinib rate above the threshold of $1,000 \mathrm{ng} / \mathrm{ml}$ appears to be important for achieving a complete cytogenetic response. This threshold is consistent 
with the one reported in the study by Picard et al (76), which involved 68 patients treated with imatinib for $\geq 1$ year at a dose of 400 or $600 \mathrm{mg} /$ day. The trough plasma concentrations of imatinib were significantly higher in patients with a major molecular response, $1,452 \pm 649 \mathrm{ng} / \mathrm{ml}$ vs. $869 \pm 427 \mathrm{ng} / \mathrm{ml}$ $(\mathrm{P}<0.001)$, or a complete cytogenetic response.

Certain studies have demonstrated that there is an association between the plasma levels of imatinib and the clinical response of patients treated for GIST $(1,100 \mathrm{ng} / \mathrm{ml})$; however, studies on this disease are considerably rare (79-81).

With regard to imatinib, studies evaluating the feasibility and efficacy of TDM in clinical practice are almost complete, and are based on the assumption that drug plasma concentration monitoring can increase treatment efficacy and/or reduce its toxicity $(74,76)$. The threshold target of trough plasma concentrations of imatinib for patients with CML is set arbitrarily at a value of $1,000 \mathrm{ng} / \mathrm{ml}$. Drug plasma concentration monitoring is currently recommended by the European Society for Medical Oncology only for imatinib, and only in cases of treatment failure or occurrence of adverse events on patients with CML treated with imatinib $(6,82)$. Dose adjustment of imatinib, based on the drug concentration in the plasma, was applied in a clinical study (83), which involved 56 patients randomized in an intervention 'routine TDM' arm and a control 'rescue TDM' arm. The patients allocated in the 'routine TDM' arm were administered a dose targeting a C0 of $1,000 \mathrm{ng} / \mathrm{ml}$. Due to the small number of patients and the poor adherence of prescribers to the dosage recommendation (13/28), the trial could not definitively demonstrate the benefit of a 'routine TDM' of imatinib; however, the study suggested that TDM can be useful in patient management during imatinib treatment, particularly during the first 3 months (83).

TDM is useful for imatinib in particular, since its inter-individual variability interferes considerably with its efficiency, but also due to the fact that there is a marked association between dose and response (7). TDM also is important in the evaluation of compliance to daily oral therapy (18); however, for other TKIs, it is important to establish the plasma target values through clinical studies (2).

Other TKIs. It has been reported that $15-20 \%$ of patients treated with imatinib exhibit clinical resistance, which is characterized by a reduced affinity of imatinib to its targets (84). In such cases, imatinib should be substituted with a different TKI such as nilotinib or dasatinib (16). The threshold of effectiveness has been defined for imatinib; however, this is not the case for other TKIs, despite the publication of few studies on the pharmacokinetics of nilotinib (85). With regard to dasatinib, no correlation has been observed between trough concentration and therapeutic response in patients with CML or $\mathrm{Ph}^{+}$ ALL (13); however, these results are controversial, as the population pharmacokinetic model established from the data of a phase II study revealed a significant correlation between the trough plasma concentration of dasatinib $(2.5 \mathrm{ng} / \mathrm{ml})$ and a major cytogenetic response $(\mathrm{P}<0.01)(86)$. With regard to nilotinib, no significant correlation was observed between the drug plasma concentration and major molecular response at 12 months (87). Further research is required to define the role of blood level testing in cases of non-adherence or potential drug interactions (88).
In patients with advanced NSCLC treated with gefitinib at $250 \mathrm{mg} /$ day, the ratio of the minimum gefitinib concentration was calculated on day 8 (D8) and D3. A high D8/D3 ratio was significantly associated with a better progression-free survival $(\mathrm{P}=0.0129)$ (88). Another study confirmed these results by revealing that a threshold of $200 \mathrm{ng} / \mathrm{ml}$ was associated with a better median survival (4.70 vs. 14.60 months, $\mathrm{P}=0.0009$ ) (89).

With regard to sunitinib, an estimation of threshold value could be $50 \mathrm{ng} / \mathrm{ml}$ for patients with advanced solid malignancy (90), but no pharmacokinetic studies have been performed. No threshold values have been determined for erlotinib and lapatinib.

The evaluation of TKI plasma concentrations may aid to obtain optimal therapeutic results, particularly in patients who experience adverse effects and for whom the dosage should be adjusted (20). Several recent publications have reported the validity of this analytical method for the quantification of imatinib levels in blood using chromatographic techniques coupled with UV detection or MS $(6,17,18,23,30,37,45,61)$.

\section{Conclusion}

TKIs are characterized by large inter-individual variations such as genetic polymorphisms and drug-drug interactions. Furthermore, TKIs are administered orally and can be given over an extended period of time, which may occasionally lead to poor patient adherence. All these factors affecting variability can also affect the pharmacokinetics of TKIs and cause an inadequate exposure system. In the majority of clinical studies, pharmacokinetic analysis is carried out using LC coupled to MS. This method is associated with a considerably high sensitivity and specificity, and comprises the reference method for simultaneous quantification of several TKIs in the plasma. LC coupled to MS can be easily used in TDM. The marked variability of TKIs requires regular monitoring to ensure an optimal response and reduction of potential adverse effects. In cases of treatment failure, unusually severe side-effects or suspected drug interactions, measuring the trough plasma concentration of the drug may assist the clinician in the decision-making process of keeping the current treatment by adjusting the drug dosage or changing the type of drug molecule administered to the patient. The correlation between therapeutic efficacy and trough plasma concentration of drugs has been widely studied, and, in the case of imatinib, has been reported. Different thresholds have been identified for other TKIs, but the existing studies on them are limited and sometimes contradictory, thus rendering further research on therapeutic monitoring required.

\section{References}

1. McLeod HL: Therapeutic drug monitoring opportunities in cancer therapy. Pharmacol Ther 74: 39-54, 1997.

2. Yu H, Steeghs N, Nijenhuis CM, Schellens JH, Beijnen JH and Huitema AD: Practical guidelines for therapeutic drug monitoring of anticancer tyrosine kinase inhibitors: Focus on the pharmacokinetic targets. Clin Pharmacokinet 53: 305-325, 2014.

3. de Jonge ME, Huitema AD, Schellens JH, Rodenhuis S and Beijnen JH: Individualised cancer chemotherapy: Strategies and performance of prospective studies on therapeutic drug monitoring with dose adaptation: A review. Clin Pharmacokinet 44: 147-173, 2012. 
4. Mathijssen RH, de Jong FA, Loos WJ, van der Bol JM, Verweij J and Sparreboom A: Flat-fixed dosing versus body surface area based dosing of anticancer drugs in adults: Does it make a difference? Oncologist 12: 913-923, 2007.

5. Arora A and Scholar EM: Role of tyrosine kinase inhibitors in cancer therapy. J Pharmacol Exp Ther 315: 971-979, 2005.

6. Josephs DH, Fisher DS, Spicer J and Flanagan RJ: Clinical pharmacokinetics of tyrosine kinase inhibitors: Implications for therapeutic drug monitoring. Ther Drug Monit 35: 562-587, 2013.

7. Widmer N, Bardin C, Chatelut E, Paci A, Beijnen J, Levêque D, Veal $\mathrm{G}$ and Astier A: Review of therapeutic drug monitoring of anticancer drugs part two - targeted therapies. Eur J Cancer 50: 2020-2036, 2014.

8. van Erp NP, Gelderblom H and Guchelaar HJ: Clinical pharmacokinetics of tyrosine kinase inhibitors. Cancer Treat Rev 35 : 692-706, 2009.

9. Teo YL, Ho HK and Chan A: Metabolism-related pharmacokinetic drug-drug interactions with tyrosine kinase inhibitors: Current understanding, challenges and recommendations. Br J Clin Pharmacol 79: 241-253, 2015.

10. Apperley JF: Part II: Management of resistance to imatinib in chronic myeloid leukaemia. Lancet Oncol 8: 1116-1128, 2007.

11. Giles FJ, le Coutre PD, Pinilla-Ibarz J, Larson RA, Gattermann N, Ottmann OG, Hochhaus A, Radich JP, Saglio G, Hughes TP, et al: Nilotinib in imatinib-resistant or imatinib-intolerant patients with chronic myeloid leukemia in chronic phase: 48-month follow-up results of a phase II study. Leukemia 27: 107-112, 2013.

12. Hochhaus A, Kantarjian HM, Baccarani M, Lipton JH, Apperley JF, Druker BJ, Facon T, Goldberg SL, Cervantes F, Niederwieser D, et al: Dasatinib induces notable hematologic and cytogenetic responses in chronic-phase chronic myeloid leukemia after failure of imatinib therapy. Blood 109: 2303-2309, 2007.

13. Brave M, Goodman V, Kaminskas E, Farrell A, Timmer W, Pope S, Harapanhalli R, Saber H, Morse D, Bullock J, et al: Sprycel for chronic myeloid leukemia and Philadelphia chromosome-positive acute lymphoblastic leukemia resistant to or intolerant of imatinib mesylate. Clin Cancer Res 14: 352-359, 2008.

14. Mathisen MS, Kantarjian HM, Cortes J and Jabbour EJ: Practical issues surrounding the explosion of tyrosine kinase inhibitors for the management of chronic myeloid leukemia. Blood Rev 28: 179-187, 2014

15. Cortes JE, Kantarjian HM, Brümmendorf TH, Kim DW, Turkina AG, Shen ZX, Pasquini R, Khoury HJ, Arkin S, Volkert A, et al: Safety and efficacy of bosutinib (SKI-606) in chronic phase Philadelphia chromosome-positive chronic myeloid leukemia patients with resistance or intolerance to imatinib (erratum). Blood 122: 2524, 2013.

16. Motzer RJ, Michaelson MD, Redman BG, Hudes GR, Wilding G, Figlin RA, Ginsberg MS, Kim ST, Baum CM, DePrimo SE, et al: Activity of SU11248, a multitargeted inhibitor of vascular endothelial growth factor receptor and platelet-derived growth factor receptor, in patients with metastatic renal cell carcinoma. J Clin Oncol 24: 16-24, 2006.

17. Haouala A, Zanolari B, Rochat B, Montemurro M, Zaman K, Duchosal MA, Ris HB, Leyvraz S, Widmer N and Decosterd LA Therapeutic drug monitoring of the new targeted anticancer agents imatinib, nilotinib, dasatinib, sunitinib, sorafenib and lapatinib by LC tandem mass spectrometry. J Chromatogr B Analyt Technol Biomed Life Sci 877: 1982-1996, 2009.

18. Pirro E, De Francia S, De Martino F, Fava C, Ulisciani S, Cambrin GR, Racca S, Saglio G and Di Carlo F: A new HPLC-UV validated method for therapeutic drug monitoring of tyrosine kinase inhibitors in leukemic patients. J Chromatogr Sci 49: 753-757, 2011.

19. Saita T, Shin M and Fujito H: Development of a specific and sensitive enzyme-linked immunosorbent assay for the quantification of imatinib. Biol Pharm Bull 36: 1964-1968, 2013.

20. Götze L, Hegele A, Metzelder SK, Renz H and Nockher WA: Development and clinical application of a LC-MS/MS method for simultaneous determination of various tyrosine kinase inhibitors in human plasma. Clin Chim Acta 413: 143-149, 2012

21. Ajimura TO, Borges KB, Ferreira AF, de Castro FA and de Gaitani CM: Capillary electrophoresis method for plasmatic determination of imatinib mesylate in chronic myeloid leukemia patients. Electrophoresis 32: 1885-1892, 2011.

22. Rezende VM, Rivellis AJ, Gomes MM, Dörr FA, Novaes MM, Nardinelli L, Costa AL, Chamone DA and Bendit I: Determination of serum levels of imatinib mesylate in patients with chronic myeloid leukemia: Validation and application of a new analytical method to monitor treatment compliance. Rev Bras Hematol Hemoter 35: 103-108, 2013.
23. Roth O, Spreux-Varoquaux O, Bouchet $S$, Rousselot $P$ Castaigne S, Rigaudeau S, Raggueneau V, Therond P, Devillier P, Molimard M and Maneglier B: Imatinib assay by HPLC with photodiode-array UV detection in plasma from patients with chronic myeloid leukemia: Comparison with LC-MS/MS. Clin Chim Acta 411: 140-146, 2010.

24. Widmer N, Béguin A, Rochat B, Buclin T, Kovacsovics T, Duchosal MA,Leyvraz S, Rosselet A, Biollaz J and Decosterd LA: Determination of imatinib (Gleevec) in human plasma by solid-phase extraction-liquid chromatography-ultraviolet absorbance detection. J Chromatogr B Analyt Technol Biomed Life Sci 803: 285-292, 2004.

25. Velpandian T, Mathur R, Agarwal NK, Arora B, Kumar L and Gupta SK: Development and validation of a simple liquid chromatographic method with ultraviolet detection for the determination of imatinib in biological samples. J Chromatogr B Analyt Technol Biomed Life Sci 804: 431-434, 2004.

26. Bende G, Kollipara S, Movva S, Moorthy G and Saha R: Validation of an HPLC method for determination of imatinib mesylate in rat serum and its application in a pharmacokinetic study. J Chromatogr Sci 48: 334-341, 2010.

27. Pursche S, Ottmann OG, Ehninger G and Schleyer E: High-performance liquid chromatography method with ultraviolet detection for the quantification of the BCR-ABL inhibitor nilotinib (AMN107) in plasma, urine, culture medium and cell preparations. J Chromatogr B Analyt Technol Biomed Life Sci 852: 208-216, 2007.

28. Miura M, Takahashi N and Sawada K: High-performance liquid chromatography with solid-phase extraction for the quantitative determination of nilotinib in human plasma. Biomed Chromatogr 24: 789-793, 2010.

29. Yuki M, Yamakawa Y, Uchida T, Nambu T, Kawaguchi T, Hamada A and Saito H: High-performance liquid chromatographic assay for the determination of nilotinib in human plasma. Biol Pharm Bull 34: 1126-1128, 2011.

30. Davies A, Hayes AK, Knight K, Watmough SJ, Pirmohamed M and Clark RE: Simultaneous determination of nilotinib, imatinib and its main metabolite (CGP-74588) in human plasma by ultra-violet high performance liquid chromatography. Leuk Res 34: 702-707, 2010.

31. Faivre L, Gomo C, Mir O, Taieb F, Schoemann-Thomas A, Ropert S, Vidal M, Dusser D, Dauphin A, Goldwasser F and Blanchet B: A simple HPLC-UV method for the simultaneous quantification of gefitinib and erlotinib in human plasma. J Chromatogr B Analyt Technol Biomed Life Sci 879: 2345-2350, 2011.

32. Afify S, Rapp UR and Högger P: Validation of a liquid chromatography assay for the quantification of the Raf kinase inhibitor BAY 43-9006 in small volumes of mouse serum. J Chromatogr B Analyt Technol Biomed Life Sci 809: 99-103, 2004.

33. Blanchet B, Billemont B, Cramard J, Benichou AS, Chhun S, Harcouet L, Ropert S, Dauphin A, Goldwasser F and Tod M: Validation of an HPLC-UV method for sorafenib determination in human plasma and application to cancer patients in routine clinical practice. J Pharm Biomed Anal 49: 1109-1114, 2009.

34. Blanchet B, Saboureau C, Benichou AS, Billemont B, Taieb F, Ropert S, Dauphin A, Goldwasser F and Tod M: Development and validation of an HPLC-UV-visible method for sunitinib quantification in human plasma. Clin Chim Acta 404: 134-139, 2009.

35. Zhen Y, Thomas-Schoemann A, Sakji L, Boudou-Rouquette P, Dupin N, Mortier L, Vidal M, Goldwasser F and Blanchet B: An HPLC-UV method for the simultaneous quantification of vemurafenib and erlotinib in plasma from cancer patients. J Chromatogr B Analyt Technol Biomed Life Sci 928: 93-97, 2013.

36. Jones HK, Stafford LE, Swaisland HC and Payne R: A sensitive assay for ZD1839 (Iressa) in human plasma by liquid-liquid extraction and high performance liquid chromatography with mass spectrometric detection: Validation and use in Phase I clinical trials. J Pharm Biomed Anal 29: 221-228, 2002.

37. Rezende VM, Rivellis A, Novaes MM, de Alencar Fisher Chamone D and Bendit I: Quantification of imatinib in human serum: Validation of a high-performance liquid chromatography-mass spectrometry method for therapeutic drug monitoring and pharmacokinetic assays. Drug Des Devel Ther 7: 699-710, 2013.

38. De Francia S, D'Avolio A, De Martino F, Pirro E, Baietto L, Siccardi M, Simiele M, Racca S, Saglio G, Di Carlo F and Di Perri G: New HPLC-MS method for the simultaneous quantification of the antileukemia drugs imatinib, dasatinib, and nilotinib in human plasma. J Chromatogr B Analyt Technol Biomed Life Sci 877: 1721-1726, 2009. 
39. Sparidans RW, Iusuf D, Schinkel AH, Schellens JH and Beijnen JH: Liquid chromatography-tandem mass spectrometric assay for the light sensitive tyrosine kinase inhibitor axitinib in human plasma. J Chromatogr B Analyt Technol Biomed Life Sci 877: 4090-4096, 2009.

40. Furlong MT, Agrawal S, Hawthorne D, Lago M, Unger S, Krueger L and Stouffer B: A validated LC-MS/MS assay for the simultaneous determination of the anti-leukemic agent dasatinib and two pharmacologically active metabolites in human plasma: Application to a clinical pharmacokinetic study. J Pharm Biomed Anal 58: 130-135, 2012

41. Zhao M, He P, Rudek MA, Hidalgo M and Baker SD: Specific method for determination of OSI-774 and its metabolite OSI-420 in human plasma by using liquid chromatography-tandem mass spectrometry. J Chromatogr B Analyt Technol Biomed Life Sci 793: 413-420, 2003.

42. Masters AR, Sweeney CJ and Jones DR: The quantification of erlotinib (OSI-774) and OSI-420 in human plasma by liquid chromatography-tandem mass spectrometry. J Chromatogr B Analyt Technol Biomed Life Sci 848: 379-383, 2007.

43. Thappali SR, Varanasi K, Veeraraghavan S, Arla R, Chennupati S, Rajamanickam M, Vakkalanka S and Khagga M: Simultaneous determination of celecoxib, erlotinib, and its metabolite desmethyl-erlotinib (OSI-420) in rat plasma by liquid chromatography/tandem mass spectrometry with positive/negative ion-switching electrospray ionisation. Sci Pharm 80: 633-646, 2012.

44. Wang LZ, Lim MY, Chin TM, Thuya WL, Nye PL, Wong A, Chan SY, Goh BC and Ho PC: Rapid determination of gefitinib and its main metabolite, O-desmethyl gefitinib in human plasma using liquid chromatography-tandem mass spectrometry. J Chromatogr B Analyt Technol Biomed Life Sci 879: 2155-2161, 2011.

45. Moreno JM, Wojnicz A, Steegman JL, Cano-Abad MF and Ruiz-Nuño A: Imatinib assay by high-performance liquid chromatography in tandem mass spectrometry with solid-phase extraction in human plasma. Biomed Chromatogr 27: 502-508, 2013.

46. Titier K, Picard S, Ducint D, Teilhet E, Moore N, Berthaud P, Mahon FX and Molimard M: Quantification of imatinib in human plasma by high-performance liquid chromatography-tandem mass spectrometry. Ther Drug Monit 27: 634-640, 2005.

47. Bianchi F, Caffarri E, Cavalli S, Lagrasta C, Musci M, Quaini F and Savi M: Development and validation of an high performance liquid chromatography-tandem mass spectrometry method for the determination of imatinib in rat tissues. J Pharm Biomed Anal 73: 103-107, 2013.

48. Bakhtiar R, Khemani L, Hayes M, Bedman T and Tse F: Quantification of the anti-leukemia drug STI571 (Gleevec) and its metabolite (CGP 74588) in monkey plasma using a semi-automated solid phase extraction procedure and liquid chromatography-tandem mass spectrometry. J Pharm Biomed Anal 28: 1183-1194, 2002.

49. Bakhtiar R, Lohne J, Ramos L, Khemani L, Hayes M and Tse F: High-throughput quantification of the anti-leukemia drug STI571 (Gleevec) and its main metabolite (CGP 74588) in human plasma using liquid chromatography-tandem mass spectrometry. J Chromatogr B Analyt Technol Biomed Life Sci 768: 325-340, 2002

50. Parise RA, Ramanathan RK, Hayes MJ and Egorin MJ: Liquid chromatographic-mass spectrometric assay for quantitation of imatinib and its main metabolite (CGP 74588) in plasma. J Chromatogr B Analyt Technol Biomed Life Sci 791: 39-44, 2003

51. Bai F, Freeman BB III, Fraga CH, Fouladi M and Stewart CF: Determination of lapatinib (GW572016) in human plasma by liquid chromatography electrospray tandem mass spectrometry (LC-ESI-MS/MS). J Chromatogr B Analyt Technol Biomed Life Sci 831: 169-175, 2006.

52. Minocha M, Khurana V and Mitra AK: Determination of pazopanib (GW-786034) in mouse plasma and brain tissue by liquid chromatography-tandem mass spectrometry (LC/MS-MS). J Chromatogr B Analyt Technol Biomed Life Sci 901: 85-92, 2012.

53. Minkin P, Zhao M, Chen Z, Ouwerkerk J, Gelderblom H and Baker SD: Quantification of sunitinib in human plasma by high-performance liquid chromatography-tandem mass spectrometry. J Chromatogr B Analyt Technol Biomed Life Sci 874 $84-88,2008$

54. Zhou Q and Gallo JM: Quantification of sunitinib in mouse plasma, brain tumor and normal brain using liquid chromatography-electrospray ionization-tandem mass spectrometry and pharmacokinetic application. J Pharm Biomed Anal 51: 958-964, 2010
55. Oberoi RK, Mittapalli RK, Fisher J and Elmquist WF: Sunitinib LC-MS/MS assay in mouse plasma and brain tissue: Application in CNS distribution studies. Chromatographia 76: 76, 2013.

56. Luethi D, Durmus S, Schinkel AH, Schellens JH, Beijnen JH and Sparidans RW: Liquid chromatography-tandem mass spectrometric assay for the multikinase inhibitor regorafenib in plasma. Biomed Chromatogr 28: 1366-1370, 2014.

57. Alvarez JC, Funck-Brentano E, Abe E, Etting I, Saiag P and Knapp A: A LC/MS/MS micro-method for human plasma quantification of vemurafenib. Application to treated melanoma patients. J Pharm Biomed Anal 97: 29-32, 2014.

58. Nijenhuis CM, Rosing H, Schellens JH and Beijnen JH: Development and validation of a high-performance liquid chromatography-tandem mass spectrometry assay quantifying vemurafenib in human plasma. J Pharm Biomed Anal 88: 630-635, 2014

59. Honeywell R, Yarzadah K, Giovannetti E, Losekoot N, Smit EF, Walraven M, Lind JS, Tibaldi C, Verheul HM and Peters GJ: Simple and selective method for the determination of various tyrosine kinase inhibitors used in the clinical setting by liquid chromatography tandem mass spectrometry. J Chromatogr B Analyt Technol Biomed Life Sci 878: 1059-1068, 2010.

60. Lankheet NA, Blank CU, Mallo H, Adriaansz S, Rosing H, Schellens JH, Huitema AD and Beijnen JH: Determination of sunitinib and its active metabolite N-desethylsunitinib in sweat of a patient. J Anal Toxicol 35: 558-565, 2011.

61. Couchman L, Birch M, Ireland R, Corrigan A, Wickramasinghe S, Josephs D, Spicer J and Flanagan RJ: An automated method for the measurement of a range of tyrosine kinase inhibitors in human plasma or serum using turbulent flow liquid chromatography-tandem mass spectrometry. Anal Bioanal Chem 403: 1685-1695, 2012.

62. Veeraraghavan S, Thappali S, Viswanadha S, Chennupati S, Nalla S, Golla M, Vakkalanka S and Rangasamy M: Simultaneous quantification of ruxolitinib and nilotinib in rat plasma by LC-MS/MS: Application to a pharmacokinetic study. J Pharm Biomed Anal 94: 125-131, 2014.

63. de Bruijn P, Sleijfer S, Lam MH, Mathijssen RH, Wiemer EA and Loos WJ: Bioanalytical method for the quantification of sunitinib and its N-desethyl metabolite SU12662 in human plasma by ultra performance liquid chromatography/tandem triple-quadrupole mass spectrometry. J Pharm Biomed Anal 51: 934-941, 2010.

64. Bihan K, Sauzay C, Goldwirt L, Charbonnier-Beaupel F, Hulot JS, Funck-Brentano C and Zahr N: Development and validation of a rapid and simple LC-MS/MS method for quantification of vemurafenib in human plasma: Application to a human pharmacokinetic study. Ther Drug Monit 37: 132-136, 2015.

65. Bouchet S, Chauzit E, Ducint D, Castaing N, Canal-Raffin M, Moore N, Titier K and Molimard M: Simultaneous determination of nine tyrosine kinase inhibitors by 96 -well solid-phase extraction and ultra performance LC/MS-MS. Clin Chim Acta 412: 1060-1067, 2011.

66. van Erp NP, de Wit D, Guchelaar HJ, Gelderblom H, Hessing TJ and Hartigh J: A validated assay for the simultaneous quantification of six tyrosine kinase inhibitors and two active metabolites in human serum using liquid chromatography coupled with tandem mass spectrometry. J Chromatogr B Analyt Technol Biomed Life Sci 937: 33-43, 2013.

67. Martins DH, Wagner SC, Dos Santos TV, Lizot LL, Antunes MV, Capra $\mathrm{M}$ and Linden R: Monitoring imatinib plasma concentrations in chronic myeloid leukemia. Rev Bras Hematol Hemoter 33: 302-306, 2011.

68. Haura EB, Tanvetyanon T, Chiappori A, Williams C, Simon G, Antonia S, Gray J, Litschauer S, Tetteh L, Neuger A, et al: Phase I//II study of the Src inhibitor dasatinib in combination with erlotinib in advanced non-small cell lung cancer. J Clin Oncol 28: 1387-1394, 2010.

69. Osterberg L and Blaschke T: Adherence to medication. N Engl J Med 353: 487-497, 2005.

70. Marin D, Bazeos A, Mahon FX, Eliasson L, Milojkovic D, Bua M, Apperley JF, Szydlo R, Desai R, Kozlowski K, et al: Adherence is the critical factor for achieving molecular responses in patients with chronic myeloid leukemia who achieve complete cytogenetic responses on imatinib. J Clin Oncol 28: 2381-2388, 2010.

71. Klümpen HJ, Samer CF, Mathijssen RH, Schellens JH and Gurney H: Moving towards dose individualization of tyrosine kinase inhibitors. Cancer Treat Rev 37: 251-260, 2011.

72. Opdam FL, Gelderblom H and Guchelaar HJ: Phenotyping drug disposition in oncology. Cancer Treat Rev 38: 715-725, 2012 . 
73. Pajares B, Torres E, Trigo JM, Sáez MI, Ribelles N, Jiménez B and Alba E: Tyrosine kinase inhibitors and drug interactions: A review with practical recommendations. Clin Transl Oncol 14: 94-101, 2012

74. Larson RA, Druker BJ, Guilhot F, O'Brien SG, Riviere GJ, Krahnke T, Gathmann I and Wang Y; IRIS (International Randomized Interferon vs STI571) Study Group: Imatinib pharmacokinetics and its correlation with response and safety in chronic-phase chronic myeloid leukemia: A subanalysis of the IRIS study. Blood 111: 4022-4028, 2008.

75. Peng B, Hayes M, Resta D, Racine-Poon A, Druker BJ, Talpaz M, Sawyers CL, Rosamilia M, Ford J, Lloyd P and Capdeville R: Pharmacokinetics and pharmacodynamics of imatinib in a phase I trial with chronic myeloid leukemia patients. J Clin Oncol 22: 935-942, 2004.

76. Picard S, Titier K, Etienne G, Teilhet E, Ducint D, Bernard MA, Lassalle R, Marit G, Reiffers J, Begaud B, et al: Trough imatinib plasma levels are associated with both cytogenetic and molecular responses to standard-dose imatinib in chronic myeloid leukemia. Blood 109: 3496-3499, 2007.

77. Awidi A, Ayed AO, Bsoul N, Magablah A, Mefleh R, Dweiri M, Ramahi M, Arafat E, Bishtawi M and Marie L: Relationship of serum imatinib trough level and response in CML patients: Long term follow-up. Leuk Res 34: 1573-1575, 2010

78. Kawaguchi T, Hamada A, Hirayama C, Nakashima R, Nambu T, Yamakawa Y, Watanabe H, Horikawa K, Mitsuya H and Saito H: Relationship between an effective dose of imatinib, body surface area, and trough drug levels in patients with chronic myeloid leukemia. Int J Hematol 89: 642-648, 2009.

79. Demetri GD, Wang Y, Wehrle E, Racine A, Nikolova Z, Blanke CD, Joensuu $\mathrm{H}$ and von Mehren M: Imatinib plasma levels are correlated with clinical benefit in patients with unresectable/metastatic gastrointestinal stromal tumors. J Clin Oncol 27: 3141-3147, 2009.

80. Delbaldo C, Chatelut E, Ré M, Deroussent A, Séronie-Vivien S, Jambu A, Berthaud P, Le Cesne A, Blay JY and Vassal G: Pharmacokinetic-pharmacodynamic relationships of imatinib and its main metabolite in patients with advanced gastrointestinal stromal tumors. Clin Cancer Res 12: 6073-6078, 2006.

81. Yoon S, Ryu MH, Yoo C, Beck MY, Ryoo BY and Kang YK: Imatinib plasma monitoring-guided dose modification for managing imatinib-related toxicities in gastrointestinal stromal tumor patients. J Korean Med Sci 28: 1248-1252, 2013.
82. Baccarani $\mathrm{M}$ and Dreyling $\mathrm{M}$; ESMO Guidelines Working Group: Chronic myelogenous leukemia: ESMO clinical recommendations for diagnosis, treatment and follow-up. Ann Oncol 20 (Suppl 4): S105-S107, 2009.

83. Gotta V, Widmer N, Decosterd LA, Chalandon Y, Heim D, Gregor M, Benz R, Leoncini-Franscini L, Baerlocher GM, Duchosal MA, et al: Clinical usefulness of therapeutic concentration monitoring for imatinib dosage individualization: Results from a randomized controlled trial. Cancer Chemother Pharmacol 74: 1307-1319, 2014.

84. Deininger MW: Milestones and monitoring in patients with CML treated with imatinib. Hematology Am Soc Hematol Educ Program 2008: 419-426, 2008.

85. Kantarjian H, Giles F, Wunderle L, Bhalla K, O'Brien S, Wassmann B, Tanaka C, Manley P, Rae P, Mietlowski W, et al: Nilotinib in imatinib-resistant CML and Philadelphia chromosome-positive ALL. N Engl J Med 354: 2542-2551, 2006.

86. Wang X, Roy A, Hochhaus A, Kantarjian HM, Chen TT and Shah NP: Differential effects of dosing regimen on the safety and efficacy of dasatinib: Retrospective exposure-response analysis of a phase III study. Clin Pharmacol 5: 85-97, 2013.

87. Larson RA, Yin OQ, Hochhaus A, Saglio G, Clark RE, Nakamae H, Gallagher NJ, Demirhan E, Hughes TP, Kantarjian HM and le Coutre PD: Population pharmacokinetic and exposure-response analysis of nilotinib in patients with newly diagnosed $\mathrm{Ph}^{+}$chronic myeloid leukemia in chronic phase. Eur J Clin Pharmacol 68: 723-733, 2012.

88. Nakamura Y, Sano K, Soda H, Takatani H, Fukuda M, Nagashima S, Hayashi T, Oka M, Tsukamoto K and Kohno S: Pharmacokinetics of gefitinib predicts antitumor activity for advanced non-small cell lung cancer. J Thorac Oncol 5: 1404-1409, 2010

89. Zhao YY, Li S, Zhang Y, Zhao HY, Liao H, Guo Y, Shi YX, Jiang W, Xue C and Zhang L: The relationship between drug exposure and clinical outcomes of non-small cell lung cancer patients treated with gefitinib. Med Oncol 28: 697-702, 2011.

90. Faivre S, Delbaldo C, Vera K, Robert C, Lozahic S, Lassau N, Bello C, Deprimo S, Brega N, Massimini G, et al: Safety, pharmacokinetic, and antitumor activity of SU11248, a novel oral multitarget tyrosine kinase inhibitor, in patients with cancer. J Clin Oncol 24: 25-35, 2006. 